DOI: 10.12957/demetra.2016.18304

\title{
Efeito dos nutrientes e substâncias alimentares na função tireoidiana e no hipotireoidismo
}

\section{Effect of nutrients and dietary substances on thyroid function and hypothyroidism}

\author{
Thais Regina Mezzomo' \\ Juliana Nadal ${ }^{2}$ \\ 1 Universidade Positivo, Curso de Nutrição. \\ Curitiba-PR, Brasil. \\ ${ }^{2}$ SESI - Departamento Regional do Estado do \\ Paraná, SESI/PR. Curitiba-PR, Brasil. \\ Correspondência / Correspondence \\ Thais Regina Mezzomo \\ E-mail: thaismezzomo@yahoo.com.br
}

\section{Resumo}

Este artigo teve como objetivo elaborar uma revisão de literatura sobre nutrientes e substâncias alimentares que podem impactar na função tireoidiana. Foi realizada revisão bibliográfica utilizando associação entre os descritores "hipotireoidismo", "iodo", "selênio", "zinco", "soja", "glúten" e "flavonoides", na base de dados Pubmed, em 2014. Foram encontrados 172 artigos e eleitos 42 , além de materiais necessários para alcançar o objetivo destse estudo. Observou-se que o iodeto participa da reação de organificação e posteriormente se acopla a resíduos de tirosil para formar os hormônios tireoidianos. Quantidades excessivas ou deficitárias de iodo contribuem para alterações tireoidianas, entre as quais o hipotireoidismo. O selênio e o zinco são cofatores para reações de deiodinação, as quais transformam a tiroxina (T4) em tri-iodotironina (T3) perifericamente. A deficiência desses minerais pode ser desenvolvida em dietas restritivas ou alimentação desequilibrada em qualquer fase da vida, colaborando com a diminuição da produção dos hormônios tireoidianos. Substâncias ingeridas por meio da alimentação, como o tiocianato e o isotiocianato, podem competir com o iodeto pela entrada nos folículos tireoidianos e comprometer a síntese dos hormônios, bem como a soja, que pode inibir a tireoperoxidase, enzima responsável pela oxidação do iodeto e formação dos hormônios tireoidianos, quando há deficiência de iodo. Estudos in vivo que demonstrem o tipo e a quantidade de flavonoides que podem interferir na conversão do T4 em T3 devem ser realizados, bem como estudos para elucidação do papel da isenção do glúten na reversão de hipotireoidismo subclínico.

Palavras-chave: Doenças da Glândula Tireoide. Deficiência de Iodo. Tiroxina. Selênio. Soja. 


\section{Abstract}

This article aims to develop a literature review of food nutrients and substances that can impact on thyroid function. A literature review using association between hypothyroidism descriptors, iodine, selenium, zinc, soy, gluten and flavonoids was held in Pubmed database in 2014. It was found 172 articles and 42 were elected, besides material needed to achieve the objective of this study. It was observed that iodide participates in the reaction organification and subsequently engages tyrosyl residues to form the thyroid hormones. Excessive or deficient amounts of iodine contribute to thyroid dysfunction, including hypothyroidism. Selenium and zinc are co-factors for deiodination reactions, which convert thyroxine (T4) in triiodothyronine (T3) peripherally. Deficiency of these minerals can be developed on restrictive diets or unbalanced diet at any stage of life, collaborating with decreased production of thyroid hormones. Furthermore, intaken substances, such as thiocyanate and isothiocyanate can compete with iodide for the entry in thyroid follicles and compromise hormones synthesis, as well as soy, which can inhibit thyroid peroxidase, enzyme responsible for the oxidation of iodide and formation of thyroid hormones, when there is iodine deficiency. In vivo studies that show the type and amount of flavonoids that may interfere with the conversion of T4 to T3 should be performed, as well as studies to elucidate the role of the exemption of gluten in the reversal of subclinical hypothyroidism.

Key words: Thyroid Gland. Iodine Deficiency. Thyroxine. Selenium. Soybeans.

\section{Introdução}

Dentre as alterações endócrinas mais comuns, destacam-se as desordens da glândula tireoide, em especial o hipotireoidismo. A tireoide secreta dois importantes hormônios, a tiroxina (T4) e a tri-iodotironina (T3), ambas com efeito de controlar o crescimento, o metabolismo e o desenvolvimento corporal, desempenhando funções na produção de proteínas estruturais, enzimas e outros hormônios. ${ }^{1}$ Contudo, o papel mais importante dos hormônios é a estimulação do metabolismo, pois em geral eles aumentam o metabolismo das proteínas, dos lipídeos e dos carboidratos. Também elevam o consumo de oxigênio e a produção de calor, manifestada por uma elevação na taxa metabólica basal. ${ }^{2}$

Para que ocorra a síntese e a função adequada dos hormônios da tireoide (HTs), são requeridos muitos micronutrientes como iodo, selênio e zinco. Outras substâncias provenientes da ingestão 
de alimentos podem influenciar no funcionamento da tireoide, dentre as quais os glicosinolatos, o glúten, as isoflavonas e os flavonoides. ${ }^{3}$

O hipotireoidismo, estado clínico resultante da deficiência de HTs, é responsável por várias alterações corporais, que podem induzir doenças crônicas não transmissíveis (DCNT) como obesidade, dislipidemias e até mesmo algumas neoplasias. ${ }^{4}$ Ressalta-se, no entanto, que a dieta é um dos fatores de risco para o surgimento e o agravamento do hipotireoidismo. ${ }^{1}$

A influência dos nutrientes na função tireoidiana ainda é um tanto quanto nebulosa para a ciência, fato este que revela a necessidade de estímulo a novas pesquisas no sentido de ampliar o conhecimento nessa área, para que medidas preventivas ou de apoio ao tratamento possam ser tomadas e auxiliem efetivamente na adequação do funcionamento da tireoide. Dessa forma, o objetivo deste estudo foi elaborar uma revisão de literatura sobre os nutrientes e substâncias alimentares que podem impactar na função tireoidiana, principalmente no que diz respeito ao hipotireoidismo.

\section{Métodos}

Elaborou-se pesquisa bibliográfica com base em artigos científicos que apresentavam associação entre o descritor "hipotireoidismo" (hypothyroidism) e os seguintes descritores: iodo (iodine), selênio (selenium), soja (soy), zinco (zinc), glúten (gluten) e flavonoides (flavonoid), apenas na base de dados Pubmed via National Library of Medicine em 2014. Foram encontrados 172 artigos.

Os critérios adotados para seleção dos artigos foram a abordagem sobre o hipotireoidismo e doenças da tireoide relacionados aos descritores já mencionados, sendo excluídos desta pesquisa os materiais bibliográficos que não estavam diretamente ligados ao escopo desta revisão, embora apresentassem os descritores selecionados. Dessa forma, selecionaram-se 42 artigos. Foram adicionados quatro livros, uma diretriz brasileira, uma Resolução de Diretoria Colegiada, uma tabela de composição de alimentos, um documento sobre ingestão dietética recomendada, uma Pesquisa de Orçamentos Familiares e sete outros artigos pertinentes ao assunto abordado.

\section{Síntese, armazenamento e secreção dos hormônios tireoidianos}

A secreção glandular dos HTs é regulada por uma alça de retroalimentação que envolve o hipotálamo, a hipófise e a glândula tireoide. O receptor do hormônio liberador de tireotropina (TRH) hipotalâmico estimula a produção hipofisária do hormônio estimulante da tireoide (TSH), que, por sua vez, estimula a síntese e a secreção dos HTs, como representado na figura 1. O TSH, secretado pelas células tireotrópicas da adeno-hipófise, desempenha papel fundamental no controle do eixo tireoideo e serve como marcador fisiológico extremamente útil na ação dos HTs. ${ }^{4}$ 


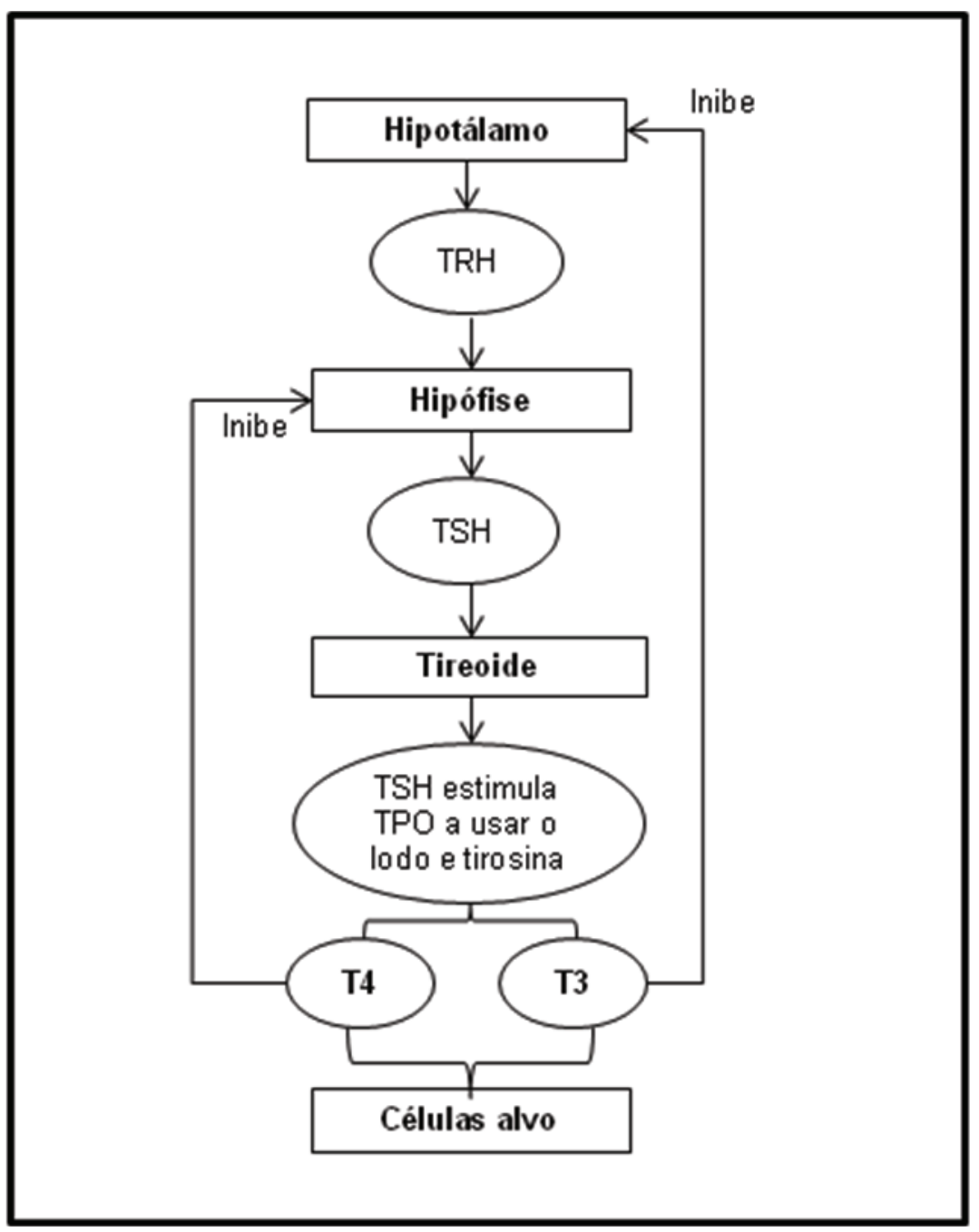

Legenda: TRH: hormônio liberador de tireotropina; TSH: hormônio estimulante da tireoide; TPO: peroxidase da tireoide; T4: tiroxina; T3: tri-iodotironina.

Fonte: adaptado de Goldfeder ${ }^{10}$.

Figura 1. Produção dos hormônios tireoidianos 
Aproximadamente 90\% dos hormônios secretados pela glândula tireoide são de T4 e apenas 10\% de T3, sendo este o hormônio bioativo. Contudo, considerável quantidade de T4 é convertida em T3 nos tecidos periféricos, de forma que ambos são importantes funcionalmente. Cerca de $80 \%$ do T3 são gerados no fígado e nos rins pela enzima 5'-desiodase (5'D), que remove uma molécula de iodo do T4 para formar o T3 ou rT3. ${ }^{5}$

As funções desses dois hormônios são qualitativamente as mesmas, mas diferem quanto a velocidade e intensidade de ação. O T3 é cerca de quatro vezes mais potente que o T4, mas está presente no sangue em quantidades muito menores e persiste por menos tempo que o $\mathrm{T} 4 .^{5}$

\section{Hipotireoidismo}

O hipotireoidismo é definido como um estado clínico resultante da deficiência de hormônios da glândula tireoide. A forma mais prevalente é o hipotireoidismo primário, ocasionado pela destruição da própria glândula, mas pode ocorrer também devido a doença hipotalâmica ou hipofisária, sendo denominado como hipotireoidismo central. ${ }^{6}$

O hipotireoidismo primário é comum e acomete quase $5 \%$ dos indivíduos. É mais comumente diagnosticado em mulheres em idades avançadas, embora ocorra em homens e em indivíduos mais jovens. Já o hipotireoidismo central é raro, representando menos de $1 \%$ dos casos. ${ }^{2}$

A deficiência dietética de iodo é a principal causa de hipotireoidismo primário em algumas regiões subdesenvolvidas do mundo. A causa mais comum do hipotireoidismo primário nos Estados Unidos e na maioria dos outros países é a tireoidite autoimune (DAT), denominada de Hashimoto, uma condição na qual a alteração da imunidade mediada pelas células $\mathrm{T}$ provoca a destruição do tecido tireoidiano e o comprometimento da função glandular. ${ }^{2}$ Outras causas comuns de hipotireoidismo são a remoção cirúrgica da glândula ou a terapia de radiação da tireoide, medicamentos que danificam a glândula e defeitos genéticos que afetam os HTs. ${ }^{6}$

O hipotireoidismo subclínico, também conhecido como doença tireoidiana mínima, é evidenciado quando os níveis de HTs estão dentro do valor de referência laboratorial, mas o TSH encontra-se elevado. Pode sugerir uma falência inicial da glândula tireoide com ausência de sintomas. Sua prevalência aumenta com a idade e afeta até $18 \%$ dos idosos, com maior prevalência nas mulheres. ${ }^{7}$

As manifestações clínicas do hipotireoidismo ocorrem gradualmente e incluem: fadiga, bradicardia, rouquidão, sensibilidade ao frio, pele seca, fraqueza muscular, constipação, letargia, reprodução comprometida e memória prejudicada. Nas mudanças metabólicas, sucede uma subtração na taxa de consumo de oxigênio e diminuição na produção de calor, ocasionando queda na taxa metabólica basal e, por consequência, ganho de peso, apesar de haver diminuição do apetite. ${ }^{5}$ 


\section{Alimentos e nutrientes}

\section{Iodo}

O iodo é o elemento essencial para a síntese dos HTs, além de ser essencial para o crescimento e desenvolvimento, particularmente do cérebro e do sistema nervoso central. ${ }^{8}$ Sua deficiência é um problema de saúde pública mundial, acometendo cerca de 800 milhões de pessoas. ${ }^{3}$

O iodeto dietético é absorvido no trato gastrintestinal e captado pelos tireócitos a partir da corrente sanguínea, por intermédio de um transportador específico existente na membrana basolateral dos tireócitos, o cotransportador sódio-iodeto (em inglês Na+/ I- Symporter, NIS). A atividade do NIS é eletrogênica e dependente do gradiente de $\mathrm{Na}+$ gerado pela bomba $\mathrm{Na}+$ / $\mathrm{K}+\mathrm{ATPase}$. O transporte de iodeto através do NIS é estimulado pelo TSH e regulado pelo mecanismo de autorregulação do tireócito, no qual a atividade do NIS varia inversamente com o conteúdo glandular de iodo. ${ }^{9}$

Depois de entrar na tireoide, o iodeto é transportado para a membrana apical, onde é oxidado em uma reação de organificação que envolve a tireoperoxidase (TPO), oxidase tireoideana (ThOx) e peróxido de hidrogênio $\left(\mathrm{H}_{2} \mathrm{O}_{2}\right)$. O átomo reativo de iodo é acrescentado a resíduos tirosil (Tyr) selecionados dentro da tireoglobulina (Tg) originando as monoiodotirosinas (MIT) e as diiodotirosinas (DIT). As iodotirosinas na Tg são então acopladas por uma ligação de éter em uma reação também catalisada pela TPO. O acoplamento de duas moléculas de DIT origina o T4, enquanto que da junção de MIT e do DIT surge o T3.$^{10}$ Portanto, a formação dos HTs depende da disponibilidade de iodo na região apical da célula folicular, da síntese adequada de Tg e de enzimas envolvidas na incorporação do iodo a resíduos Tyr da molécula de Tg, etapa esta denominada "organificação do iodo". ${ }^{11}$

Em casos de baixo consumo de iodo $(<100 \mu \mathrm{g} / \mathrm{d})$, a tireoide adapta-se aumentando a secreção de TSH pela hipófise. Esse aumento de TSH eleva a depuração plasmática de iodeto inorgânico pela tireoide, através da estimulação da expressão do NIS. Contanto que a ingestão diária de iodo permaneça acima de $50 \mu \mathrm{g} / \mathrm{d}$, mesmo com uma diminuição no iodo inorgânico circulante no plasma, a absorção absoluta de iodo pela tireoide permanece adequada e o teor de iodo na tireoide encontra-se dentro dos limites normais (aproximadamente $10-20 \mathrm{mg}$ ). Abaixo desse limiar, muitos indivíduos desenvolvem bócio, hipotireoidismo e retardo mental em qualquer fase da vida. ${ }^{12}$

Em situações de deficiência de iodo, o TSH elevado estimula a produção de $\mathrm{H}_{2} \mathrm{O}_{2}$ pelas células da tireoide, que pode induzir a fibrose e destruição da glândula, impedindo o reparo celular. ${ }^{13}$

Para evitar esses problemas, várias estratégias governamentais têm sido desenvolvidas para enriquecer os alimentos com esse elemento. ${ }^{14}$ Desde 1920, a suplementação sob a forma de sal e óleo vegetal iodado produziu melhorias significativas para a população mundial. No entanto, 
determinadas subpopulações, como os vegetarianos, não atingem a ingestão adequada de iodo, mesmo em países considerados iodo-suficientes. E ainda, a redução do teor de iodo na dieta pode estar relacionada ao aumento da aderência às recomendações dietéticas de redução da ingestão de sal para prevenir ou ser coadjuvante no tratamento da hipertensão arterial. Assim, a falta de controle nutricional de iodo, após a erradicação do bócio endêmico, pode levar a distúrbios de deficiência de iodo. ${ }^{3}$

Segundo o Ministério da Saúde brasileiro, desde o estabelecimento da obrigatoriedade de adição de iodo no sal de cozinha em 1950, foram realizadas quatro pesquisas para avaliar o impacto desta intervenção no Brasil. Observou-se redução significativa nas prevalências de bócio (20,7\% em 1955; 14,1\% em 1974; 1,3\% em 1984; e 1,4\% em 2000). Ressalta-se, no entanto, que apesar deste considerável avanço do controle dos distúrbios por deficiência de iodo (DDI), ainda existe a necessidade de aperfeiçoamento das ações de prevenção e controle, uma vez que o constante monitoramento da deficiência de iodo é fundamental para evitar a reincidência..$^{15}$

Por outro lado, ingestões excessivas de iodo $(20 \mathrm{mg} /$ dia $)$ também levam à DAT e ao hipotireoidismo. ${ }^{16,17}$ Inicialmente, a captação do iodo aumenta, o que resulta em aumento do conteúdo glandular de iodo e secreção tireoidiana elevada; porém, em seguida, mecanismos reguladores começam a agir no intuito de retornar às condições normais. A administração de altas doses de iodo causa uma rápida inibição da organificação do iodo e da síntese de ThOx e T4, seguida da inibição da secreção hormonal. ${ }^{11,14}$ Esse bloqueio da organificação do iodo que ocorre na presença de altas concentrações de iodo é denominado "efeito Wolff-Chaikoff". ${ }^{9}$ Du et al. ${ }^{18}$ referem que o hipotireoidismo subclínico é mais prevalente em áreas onde há uma ingestão elevada de iodo.

O estudo de Carvalho et al. ${ }^{19}$ mostrou que $67,1 \%$ dos escolares do estado de São Paulo apresentam níveis muito elevados de excreção urinária de iodo (acima de $300 \mu \mathrm{g} / \mathrm{L}$ ) e apenas $1,9 \%$ das crianças apresentou valores inferiores a $100 \mu \mathrm{g} / \mathrm{dL}$. Estes valores elevados refletem a ingestão exagerada de iodo por meio da alimentação, seja pelo consumo excessivo de sal e/ou pelo excesso de iodo no sal de cozinha, além do recomendado pela ANVISA (entre 20 e $60 \mu \mathrm{g} / \mathrm{dia}$ ). ${ }^{20}$

A última atualização da ingestão dietética recomendada (RDA) de iodo é de $150 \mu \mathrm{g} /$ dia para adultos, $220 \mu \mathrm{g} /$ dia para gestantes e $290 \mu \mathrm{g} /$ dia para lactantes.$^{21}$ Porém, a Organização Mundial da Saúde (OMS) recomenda no mínimo $75 \mu \mathrm{g}$ de iodo ao dia, o que corresponde a $10 \mathrm{~g}$ de sal iodado. ${ }^{11}$

Segundo a Pesquisa de Orçamentos Familiares (POF 2008-2009), o brasileiro ingere em média $8,2 \mathrm{~g}$ de sal ao dia, sendo que o recomendado pela OMS é de $5 \mathrm{~g} / \mathrm{dia} .{ }^{22}$ Pode-se inferir então, com os dados apresentados, que o brasileiro consome em média, $61,5 \mu \mathrm{g}$ de iodo/dia, valor este que mantém a atividade tireoideana normal, ${ }^{12}$ mas não contempla a recomendação da OMS. ${ }^{22}$ 
O iodo se distribui amplamente pela natureza e está presente em substâncias orgânicas e inorgânicas em quantidades muito pequenas. O nível de iodo na água reflete o teor de iodo das rochas e solos da região e, consequentemente, das plantas comestíveis deste local. ${ }^{23}$ No entanto, a única fonte de iodo para os seres humanos é a alimentação; assim, existe um elevado risco de deficiência nos locais onde os alimentos consumidos provêm de áreas iodo-insuficientes. ${ }^{13}$

As principais fontes alimentares, além do sal iodado, são os frutos do mar (ostras, moluscos, mariscos e peixes de água salgada), leite e seus derivados (desde que oriundos de animais que tenham pastado em solos ricos em iodo ou alimentados com rações que contenham o nutriente), castanha do Brasil, pão e vegetais oriundos de solos ricos em iodo também são boas fontes. ${ }^{14}$

\section{Selênio}

O selênio é um elemento-traço importante para os mecanismos antioxidantes, para o sistema imunológico, e ainda participa ativamente da homeostase da glândula tireoide. ${ }^{3}$ Uma vez que o este mineral, como selenocisteína, é um cofator para a 5’D, tem recebido muita atenção no que diz respeito ao metabolismo periférico dos HTs. Como citado anteriormente, a enzima 5’D hepática converte a T4 em T3r ou em T3 ativo. Se há deficiência de selênio, a atividade das deiodinases (ID) será prejudicada. ${ }^{5}$

A glândula tireoidiana normal retém altas concentrações de selênio e expressa muitas das selenocisteínas. Estas são encontradas no centro catalítico de enzimas que protegem a tireoide de danos de radicais livres. Entre elas, estão as selenoproteínas glutationa peroxidase, ID e a família de enzimas tireodoxina redutase. ${ }^{24}$

A deiodinação é o primeiro passo da ação do HT para conferir atividade biológica ao T4, o qual é o caminho metabólico que remove um resíduo de iodo da molécula de T4 para produzir T3, a forma de curta duração mais ativa do HT. ${ }^{25}$ Três isoformas de ID (tipos I, II e III) são conhecidas, todas responsáveis pela ativação do T3 circulante e intracelular. ${ }^{3}$ As ID I e II são enzimas que catalisam a conversão de T4 em T3 pela 5’D, enquanto a ID III inativa o T4 e o T3 e os transforma em metabólitos inativos (T3r e T2, respectivamente). ${ }^{25}$

O selênio também participa de outros mecanismos como o da glutationa peroxidase (GPx), a qual possui função de oxidoredução, isto é, protege a célula do estresse oxidativo. A GSH-Px 3 (glutationa peroxidase 3), produzida e secretada pelos tireócitos, regula a concentração de $\mathrm{H}_{2} \mathrm{O}_{2}$ no lúmen folicular. Durante o processo de síntese de T3 e T4 na tireoide, a GSH-Px3 sofre influência direta do TSH, que por sua vez, estimula a produção de $\mathrm{H}_{2} \mathrm{O}_{2}$ na membrana apical. A GSH-Px3 apresenta ação antioxidante, evitando maiores danos oxidativos aos tireócitos. Na deficiência de selênio, a resposta apoptótica ao $\mathrm{H}_{2} \mathrm{O}_{2}$ encontra-se aumentada. Quando em quantidades normais de selênio, o sistema tioredoxina redutase e o GSH-Px protegem os tireócitos da ação dos peróxidos. ${ }^{14}$ 
A deficiência de selênio tem sido um achado constante em doenças da glândula tireoide. ${ }^{26}$ Quando de sua deficiência, ocorrem a redução das selenoproteínas, diminuição da atividade da GSH-PX3, aumento da deiodinação, por favorecer a ação do $\mathrm{H}_{2} \mathrm{O}_{2}$ nesse processo, intoxicando os tireócitos em longo prazo e diminuição da atividade da ID I, levando a uma diminuição periférica na síntese de T3 e degradação da mesma. ${ }^{27}$ Ainda, a deficiência de selênio e a economia na produção dos HTs pode ser desenvolvida em condições especiais de dietas alimentares, tais como em nutrição parenteral total prolongada, dieta para fenilcetonúria, fibrose cística, ou pode ser o resultado de uma alimentação desequilibrada em crianças, idosos ou enfermos. ${ }^{5}$

Nas regiões com deficiência grave de iodo combinada com a de selênio, a normalização do fornecimento de iodo é obrigatória antes do início da suplementação de selênio, no sentido de impedir o hipotireoidismo. ${ }^{12}$ Desta forma, percebe-se que o selênio desempenha papel importante na regulação da função da tireoide, bem como na homeostase de HTs, através da ação de selenoproteínas, em que se incorpora como selenocisteína e, por último, protege a glândula dos danos causados pela exposição excessiva de iodeto. ${ }^{28}$

Por outro lado, o consumo de grandes quantidades de selênio também pode desencadear efeitos adversos. Tem sido demonstrado que a ingestão dietética de $300 \mu \mathrm{g}$ de selênio diária pode ter efeito tóxico sobre o fator de crescimento semelhante à insulina (IGF-1), bem como na síntese de HTs. Os principais efeitos adversos incluem anorexia, diarreia, depressão, hemorragia hepática, necrose renal, cegueira, ataxia, distúrbios respiratórios, dermatite e deficiências no sistema nervoso central. ${ }^{29}$

Drutel, Archambeaud \& Caron ${ }^{27}$ referem que em pacientes com DAT e em mulheres grávidas com anticorpos antiperoxidase tireoidiana (anti-TPO), a suplementação de selênio diminui os níveis de anticorpos anti-tireoidianos e melhora a estrutura da tireoide. E ainda, Pizzulli \& Ranjbar $^{30}$ relatam que crianças com hipotireoidismo e deficiência de selênio apresentam melhora no metabolismo tireoidiano após a suplementação de selênio, melhorando significativa de todos os sintomas clínicos, o que provavelmente se deve àa capacidade do selênio de restaurar a função da $5^{\prime}$ D. Por outro lado, Rayman et al. ${ }^{31}$ não encontraram evidências de que o efeito da suplementação de selênio beneficia a conversão de T4 para T3 em idosos. Da mesma forma, a suplementação de selênio não diminuiu as concentrações de anticorpos anti-TPO. ${ }^{32,33}$

Kandhro et al. ${ }^{34}$ observaram que a deficiência de selênio em indivíduos hipotireoideos pode desempenhar papel importante na severidade do hipotireoidismo associado com deficiência de iodo.

A RDA atual de selênio para adultos é de $55 \mu \mathrm{g} / \mathrm{dia}$. Gestantes e lactantes devem ter suas ingestões aumentadas para 60 e $70 \mu \mathrm{g} / \mathrm{dia}$, respectivamente. ${ }^{21}$ 
Estudos mostram que o consumo de selênio na população brasileira varia entre 18,5 a 114,5 $\mu \mathrm{g} /$ dia, principalmente de acordo com a região, sendo Mato Grosso e São Paulo as de menor concentração de selênio no solo e onde se constata maior deficiência alimentar desse micronutriente. ${ }^{35}$

Carnes e frutos do mar são ótimas fontes de selênio, bem como a castanha do Brasil. Contudo, a concentração de selênio nas castanhas varia de acordo com a capacidade de absorção da árvore e com a composição do solo. A concentração média de selênio em uma unidade média de castanha do Brasil é de 27,4 $\mathrm{g}$; portanto, o consumo de duas unidades diárias é suficiente para abranger a RDA. ${ }^{36} \mathrm{O}$ teor de selênio nas carnes e pescados varia entre 2,8 a $80,9 \mu \mathrm{g} / 100 \mathrm{~g}$ de alimento, sendo os pescados (atum e sardinha, principalmente) os alimentos com maior quantidade deste mineral. ${ }^{37} \mathrm{O}$ feijão preto e a farinha de trigo integral também apresentam quantidades importantes de selênio, sendo $11,9 \mu \mathrm{g} / 100 \mathrm{~g}$ e $13,6 \mu \mathrm{g} / 100 \mathrm{~g}$, respectivamente.

Não se recomenda avaliação sérica de selênio rotineiramente, pois as deficiências alimentares são raras e essencialmente associadas à desnutrição grave ou de acordo com a localização geográfica. ${ }^{27}$ Contudo, vale ressaltar que os profissionais de saúde devem ficar atentos à deficiência deste micronutriente na população de baixo poder aquisitivo, uma vez que esses alimentos são considerados onerosos. E ainda, políticas públicas devem ser estabelecidas para garantir a segurança alimentar e nutricional da população vulnerável.

\section{Zinco}

Há relatos, na literatura, de que a deficiência de zinco é uma causa de hipotireoidismo subclínico, ${ }^{38}$ pois esse mineral aumenta a atividade da ID II. ${ }^{1}$ Em estudos com animais, a deficiência de zinco resultou em diminuição de aproximadamente $30 \%$ nos níveis de T3 e T4 livres. ${ }^{39}$

Em seres humanos, a suplementação de zinco restabeleceu a função tireoidiana normal em pacientes com hipotireoidismo. No estudo de Nishiyama et al., ${ }^{40}$ realizou-se suplementação de sulfato de zinco em indivíduos que apresentavam T3 baixo, T4 livre normal e deficiência moderada de zinco, por 12 meses. A suplementação oral diminuiu os níveis séricos de T3 e T3 livre e rT3, e a TRH induzida por reação do TSH normalizou.

Kuriyama et al. ${ }^{41}$ demonstraram que concentrações séricas de zinco eritrocitário são mais baixas em pacientes com tireoidite transitória em relação aos pacientes com tireoidite permanente. Os autores sugeriram que a dosagem sérica de zinco eritrocitário pode ser útil para distinguir essas patologias e, assim, evitar a suplementação desnecessária de T4. Ainda segundo o estudo, pacientes com níveis de zinco eritrocitário inferior a $12 \mathrm{mg} / \mathrm{L}$ podem conseguir reverter o quadro de hipotireoidismo. 
A RDA de zinco é de $15 \mathrm{mg} / \mathrm{dia},{ }^{21}$ podendo essa quantidade ser encontrada em carnes e pescados, com quantidades variando entre 4 e $7,7 \mathrm{mg} / 100 \mathrm{~g}$ de alimento e em castanhas e nozes, com concentrações de 2,1 a 4,7mg/100g de alimento. ${ }^{42}$ Segundo a POF 2008-2009, 19,9\% das crianças e adolescentes e $29 \%$ dos adultos e idosos apresentam consumo inadequado desse nutriente. ${ }^{22}$

Mais estudos são necessários para esclarecer o papel do zinco na função tireoidiana.

Soja

Estudos mostram o potencial da soja para a saúde humana na prevenção de neoplasias, de doenças cardiovasculares, redução dos sintomas da menopausa, aumento da densidade mineral óssea e diminuição da resistência insulínica. Por outro lado, a soja tem gerado preocupação sobre a função da glândula tireoide. ${ }^{43}$

Pacientes com hipotireoidismo subclínico apresentam risco três vezes maior de desenvolver hipotireoidismo com suplementação de $16 \mathrm{mg}$ fitoestrógenos da soja ao dia. ${ }^{44} \mathrm{Em}$ estudo realizado com mulheres na menopausa, ${ }^{45} 75 \mathrm{mg}$ de isoflavonas reduziram os níveis de T3 livre, bem como aliviaram os sintomas da menopausa.

Pesquisas também relatam interferências da soja com a tireoide no público infantil. Bebês alimentados com fórmula de soja tiveram seus níveis de TSH aumentados quando comparados àqueles alimentados com fórmula isenta de soja. ${ }^{46}$ Outros autores referem o aparecimento de bócio em bebês alimentados com fórmula à base de soja; no entanto, esse quadro regride com a substituição da fórmula para o leite de vaca ou dietas suplementadas com iodo. ${ }^{47}$

Estudos in vitro e em animais demonstram que as isoflavonas (principalmente a genisteína e daidzeína) presentes na soja apresentam a capacidade de inibir a enzima TPO, a qual promove a iodação da tireoglobulina, importante para a síntese dos HTs. A inibição dessa enzima provoca diminuição da produção de HTs, aumenta a produção de TSH endógeno e pode induzir ao bócio e ao hipotireoidismo. ${ }^{48}$ Por outro lado, Bitto et al.$^{49}$ demonstraram que genisteína aglicona na dose de $54 \mathrm{mg} /$ dia por três anos não afetou a produção de hormônios tireoideos ou anticorpos anti-TPO em mulheres em menopausa e osteopênicas.

Segundo Messina \& Redmond, ${ }^{50}$ os resultados da literatura fornecem pouca evidência de que indivíduos eutireoideos sem deficiência de iodo apresentem efeitos adversos ao ingerirem alimentos de soja ou isoflavonas. Contudo, há uma preocupação teórica com base em estudos in vitro e em animais, de que indivíduos com função tireoidiana comprometida e/ou cuja ingestão de iodo é marginal podem aumentar o risco de desenvolver hipotireoidismo com o consumo de soja. Assim, é importante que consumidores de alimentos a base de soja certifiquem-se de que sua ingestão de iodo seja adequada. 
Além disso, a soja pode bloquear a absorção de medicamentos para a tireoide.$^{50}$ Deste modo, indivíduos com elevado consumo de soja devem ser monitorados e novas pesquisas voltadas aos malefícios e benefícios da soja para com os HTs são requeridas.

\section{Glúten}

A literatura demonstra que a doença celíaca está associada com aumento na prevalência de DAT e vice-versa, com uma prevalência de aproximadamente $9 \% .^{13,51} \mathrm{Em}$ pacientes com doença celíaca, a prevalência de hipotireoidismo é de 2 a $5 \% .^{52}$

Especula-se que a deficiência de selênio, ao reduzir a atividade da GPX, permita a oxidação de estruturas como a TPO, que, modificada, poderia ser reconhecida como antígeno, estimulando assim o surgimento e a proliferação de anticorpos anti-TPO. ${ }^{1}$ A prevalência de anticorpos antiTPO é maior em celíacos do que em indivíduos saudáveis. ${ }^{53}$

Sategna et al. ${ }^{54}$ observaram que a dieta sem glúten pode reverter a anormalidade de pessoas com hipotiroidismo subclínico, embora não tenham encontrado correlação entre o tempo de exposição ao glúten em celíacos e o risco de doenças autoimunes. Outros autores também relataram que a dieta isenta de glúten apresenta efeito protetor para doenças da tireoide e orientam que a dieta livre de glúten deve ser iniciada precocemente, antes de as desordens autoimunes estarem estabelecidas, a fim de prevenir ou minimizar seu curso. ${ }^{55}$ Contudo, outros autores discordam desses achados e referem haver pouca evidência para apoiar a dieta isenta de glúten para reduzir o desenvolvimento de DAT. ${ }^{13}$

De acordo com os dados apresentados, ainda existe polêmica a respeito da orientação de dieta isenta de glúten como forma de prevenção de DAT e hipotireoidismo. No entanto, para o tratamento da doença celíaca, deve-se utilizar obrigatoriamente dieta isenta de glúten. Dessa forma, mais estudos são necessários para esclarecer o papel do glúten na doença tireoidiana.

\section{Flavonoides}

Flavonoides, tanto sintéticos quanto de ocorrência natural, possuem potencial para interferir no metabolismo dos HTs in vitro. Derivados de flavonoides sintéticos diminuem as concentrações séricas de T4 e inibem tanto a conversão de T4 para T3 quanto a depuração metabólica de T3r pelo Se. Os flavonoides de ocorrência natural parecem ter efeito inibitório semelhante. ${ }^{56}$ A luteolina, um flavonoide natural, é o inibidor mais ativo da atividade da 5’D, quando testados in vitro, bem como a quercetina e a miricetina também apresentam atividade inibitória in vitro. ${ }^{39}$ 
Catequinas, flavonoides encontrados em abundância no chá verde, diminuem as atividades de TPO, da 5’D e dos níveis de T3 e T4, juntamente com elevação significativa de TSH. ${ }^{57}$

Ainda não está claro se efeitos semelhantes ocorrem in vivo, ou ainda, se ocorrer, se são restritos a flavonoides específicos e em quais dosagens. Uma vez isolado ou concentrado, os flavonoides são cada vez mais utilizados como intervenções terapêuticas, mas pesquisas adicionais sobre a influência potencial dessas substâncias no metabolismo de HTs são desejáveis. Cuidado deve ser tomado principalmente em indivíduos com deficiência nutricional de iodo, pois pode contribuir para o desenvolvimento de hipotireoidismo e bócio. ${ }^{39,56}$

Como exemplos de alimentos fonte, têm-se feijão, soja, milho, pinhão, brócolis e canola, que, potencialmente, poderão bloquear a incorporação de iodo pela inibição da TPO, conforme demonstrado no tópico "soja". ${ }^{23}$

\section{Brássicas}

As brássicas, brócolis, couve-flor, couve-de-bruxelas, couve-manteiga, nabo, rabanete, repolho, além de alho e cebola são fontes de glicosinolatos. Quando esses alimentos são cortados crus, ocorre interação entre os glicosinolatos e a enzima mirosinase, que catalisa a formação do tiocianato, isotiocianato e nitrila. ${ }^{1}$

O tiocianato e o isoticianato competem com o iodeto pela entrada nos folículos tireoidianos, o que pode comprometer a síntese de HTs e induzir o surgimento de bócio e do hipotireoidismo em pacientes com baixa ingestão de iodo. ${ }^{1}$

Glicosídeos cianogênicos podem ser metabolizados para tiocianatos e também competem com o iodo para serem absorvidos pela tireoide. Estão presentes em plantas tropicais como a mandioca, o feijão, a linhaça, em brotos de bambu e na batata doce. O fumo do tabaco também é fonte de tiocianato. ${ }^{58}$

A linamarina é um tioglicosídeo encontrado na mandioca, alimento básico em muitos países em desenvolvimento. Felizmente o calor inativa a linamarina e a enzima mirosinase, impedindo a formação de tiocianato e de isotiocianato. ${ }^{1,23}$

Até o momento, não há estudos que definam a quantidade de brássicas que pode afetar significativamente a síntese hormonal. ${ }^{1}$ 


\section{Considerações finais}

O iodo tem papel fundamental na produção dos HTs. Quantidades excessivas ou deficitárias de iodo e selênio contribuem para alterações tireoidianas, entre as quais o hipotireoidismo. $\mathrm{O}$ selênio e o zinco agem como cofatores nas reações de deiodinação do T4 em hormônio ativo. São necessários mais estudos para avaliar a real ingestão de iodo e selênio pela população brasileira, com a finalidade de evitar sua deficiência ou ainda, seu excesso.

Há poucas evidências de que o tiocianato, o isoticianato e as isoflavonas da soja alterem a produção de hormônios tireoidianos na ausência de deficiência de iodo. Estudos in vivo que demonstrem o tipo e a quantidade de flavonoides que podem interferir na conversão do T4 em T3 devem ser realizados, bem como estudos para elucidação do papel da isenção do glúten na reversão de hipotireoidismo subclínico.

Este estudo limitou-se a utilizar a base de dados Pubmed. Sugere-se que outras pesquisas sejam realizadas em outras bases de dados, bem como seja verificada a possível interferência de outros nutrientes ou substâncias alimentares na função tireoidiana.

\section{Referências}

1. Goldfeder RT. Tireoide e nutrição. In: Silva SMC, Mura JDP. Tratado de alimentação, nutrição e dietoterapia. $2^{\text {a }}$ ed. São Paulo: Roca; 2010. p.1003-1012.

2. Goldman L, Ausielo D. Cecil medicina. 23a ed. Rio de Janeiro: Elsevier; 2009.

3. Triggiani V, Tafaro E, Giagulli VA, Sabbà C, Resta F, Licchelli B, et al. Role of iodine, selenium and other micronutrients in thyroid function and disorders. Endocr. Metab. Immune Disord. Drug Targets 2009; 9(3):277-94.

4. Santini F, Marzullo P, Rotondi M, Ceccarini G, Pagano L, Ippolito S, et al. Mechanisms in endocrinology: the crosstalk between thyroid gland and adipose tissue: signal integration in health and disease. Eur. J. Endocrinol. 2014; 171(4):137-52.

5. Dean S. Tratamento nutricional clínico de distúrbios da tireoide e condições relacionadas. in: Mahan LK, Escott-stump S, Raymond JL. Krause alimentos, nutrição e dietoterapia. $13^{a}$ ed. Rio de Janeiro: Elsevier; 2012. p. 711-24.

6. Sociedade Brasileira de Endocrinologia e Metabolismo (SBEM), Sociedade Brasileira de Medicina da família e Comunidade (SBMFC), Associação Brasileira de Psiquiatria (ABP) [Internet]. Projeto diretrizes: hipotireoidismo: diagnóstico. diretrizes clínicas na saúde complementar. 2011. [acesso em: 23 jan. 2015]. Disponível em: http://www.projetodiretrizes.org.br/ans/diretrizes/hipotireoidismodiagnostico.pdf.

7. Baumgartner C, Blum MR, Rodondi N. Subclinical hypothyroidism: summary of evidence in 2014. Swiss Med. Wkly. 2014; 144:1-9. 
8. Pearce EN. Iodine deficiency in children. Endocr. Dev. 2014; 26:130-8.

9. Chung HR. Iodine and thyroid function. Ann. Pediatr. Endocrinol. Metab. 2014; 19(1):8-12.

10. Vaisman M, Rosenthal D, Carvalho DP. Enzimas envolvidas na organificação tireoideana do iodo. Arq. Bras. Endocrinol. Metab. 2004; 48(1):7-13.

11. Setian N. Hipotireoidismo na criança: diagnóstico e tratamento. J. Pediatr. 2007; 83(5):209-16.

12. Zimmermann MB. Iodine deficiency. Endocr. Rev. 2009; 30(4):376-408.

13. Ch'ng CL, Jones MK, Kingham JGC. Celiac disease and autoimmune thyroid disease. Clin. Med. Res. 2007; 5(3):184-192.

14. Cozzolino SF. Biodisponibilidade de nutrientes. 3a ed. Barueri, SP: Manole; 2009.

15. Brasil. Ministério da Saúde. Departamento de Atenção Básica [Internet]. Prevenção e controle de agravos nutricionais: deficiência de iodo. [acesso em: 21 jan. 2015]. Disponível em: http://dab.saude. gov.br/portaldab/ape_pcan.php

16. Tan L, Sang Z, Shen J, Liu H, Chen W, Zhao N. Prevalence of thyroid dysfunction with adequate and excessive iodine intake in Hebei Province, People's Republic of China. Public Health Nutr. 2015; 18(9):1692-1697.

17. Sun X, Shan Z, Teng W. Effects of increased iodine intake on thyroid disorders. Endocrinol. Metab. 2014; 29(3):240-247.

18. Du Y, Gao Y, Meng F, Liu S, Fan Z, Wu J, et al. Iodine deficiency and excess coexist in china and induce thyroid dysfunction and disease: a cross-sectional study. Plos One 2014; 9(11):1-11.

19. Carvalho AL, Meirelles CJ, Oliveira LA, Costa TM, Navarro AM. Excessive iodine intake in schoolchildren. Eur. J. Nutr. 2012; 51(5):557-62.

20. Brasil. Agência Nacional de Vigilância Sanitária. Resolução RDC no 130, de 26 de maio de 2003. Diário Oficial da União 28 maio 2003.

21. Institute of Medicine (US). Dietary reference intakes for vitamin a, vitamin k, arsenic, boron, chromium, copper, iodine, iron, manganese, molybdenum, nickel, silicon, vanadium, and zinc. Washington, D.C.: The National Academic Press; 2001.

22. Instituto Brasileiro de Geografia e Estatística. Pesquisa de orçamentos familiares: POF 2008-2009. Análise do consumo alimentar pessoal no Brasil. Rio de Janeiro: IBGE; 2011.

23. Pontes AAN, Adan LFF. Interferência do iodo e alimentos bociogênicos no aparecimento e evolução das tireopatias. Rev. Bras. Cienc. Saúde 2006; 10(1):81-6.

24. Köhrle J, Gärtner R. Selenium and thyroid. Best Pract. Res. Clin. Endocrinol. Metab. 2009; 23(6):815-27.

25. Larsen PR, Zavacki AM. The role of the iodothyronine deiodinases in the physiology and pathophysiology of thyroid hormone action. Eur. Thyroid. 2012; 1(4):232-42.

26. Pedersen B, Knudsen N, Carlé A, Schomburg L, Köhrle J, Jørgensen T, et al. Serum selenium is low in newly diagnosed Graves' disease: a population-based study. Clin. Endocrinol. 2013; 79(4):584-90.

27. Drutel A, Archambeaud F, Caron P. Selenium and the thyroid gland: more good news for clinicians. Clin. Endocrinol. 2013; 78(2):155-64. 
28. Watt T, Cramon P, Bjorner JB, Bonnema SJ, Feldt-Rasmussen U, Gluud C, et al. Selenium supplementation for patients with Graves' hyperthyroidism (the GRASS trial): study protocol for a randomized controlled trial. Trials 2013; 14:119.

29. Kaprara A, Krassas GE. Selenium and thyroidal function; the role of immunoassays. Hell J. Nucl. Med. 2006; 9(3):195-203.

30. Pizzulli A, Ranjbar A. Selenium deficiency and hypothyroidism: a new etiology in the differential diagnosis of hypothyroidism in children. Biol. Trace Elem. Res. 2000; 77(3):199-208.

31. Rayman MP, Thompson AJ, Bekaert B, Catterick J, Galassini R, Hall E, et al. Randomized controlled trial of the effect of selenium supplementation on thyroid function in the elderly in the United Kingdom. Am. J. Clin. Nutr. 2008; 87(2):370-8.

32. Bonfig W, Gärtner R, Schmidt H. Selenium supplementation does not decrease thyroid peroxidase antibody concentration in children and adolescents with autoimmune thyroiditis. Scientific Word Journal 2010; 10:990-96.

33. Eskes SA, Endert E, Fliers E, Birnie E, Hollenbach B, Schomburg L, et al. Selenite supplementation in euthyroid subjects with thyroid peroxidase antibodies. Clin. Endocrinol. 2014; 80(3):444-51.

34. Kandhro GA, Kazi TG, Sirajuddin, Kolachi NF, Kazi N, Afridi HI, et al. Effects of selenium supplementation on iodine and thyroid hormone status in a selected population with goitre in Pakistan. Clin. Lab. 2011; 57(7-8):575-85.

35. Cozzolino SF. Deficiências de minerais. Estud. Av. 2007; 21(60):119-26.

36. Souza ML, Menezes HC. Processamentos de amêndoa e torta de castanha-do-brasil e farinha de mandioca: parâmetros de qualidade. Ciênc. Tecnol. Aliment. 2004; 24(1):120-8.

37. Ferreira KS, Gomes JC, Bellato CR, Jordão, CP. Concentrações de selênio em alimentos consumidos no Brasil. Rev. Panam. Salud Publica 2002; 11(3):172-177.

38. Betsy A, Binitha M, Sarita S. Zinc deficiency associated with hypothyroidism: an overlooked cause of severe alopecia. Int. J. Trichology 2013; 5(1):10-2.

39. Kelly GS. Peripheral metabolism of thyroid hormones: a review. Altern. Med. Rev. 2000; 5(4):306-33.

40. Nishiyama S, Futagoishi-Suginohara Y, Matsukura M, Nakamura T, Higashi A, Shinohara M, et al. Zinc supplementation alters thyroid hormone metabolism in disabled patients with zinc deficiency. J. Am. Coll. Nutr. 1994; 13(1):62-7.

41. Kuriyama C, Mori K, Nakagawa Y, Hoshikawa S, Ozaki H, Ito S, et al. Erythrocyte zinc concentration as an indicator to distinguish painless thyroiditis-associated transient hypothyroidism from permanent hypothyroidism. Endocr. J. 2011; 58(1):59-63.

42. Universidade Estadual de Campinas. Núcleo de Estudos e Pesquisas em Alimentação. Tabela Brasileira de Composição de Alimentos - TACO. 4a ed. Campinas: NEPA-UNICAMP; 2011.

43. Tran L, Hammuda M, Wood C, Xiao CW. Soy extracts suppressed iodine uptake and stimulated the production of autoimmunogen in rat thyrocytes. Exp. Biol. Med. 2013; 238(6):623-30. 
44. Sathyapalan T, Manuchehri AM, Thatcher NJ, Rigby AS, Chapman T, Kilpatrick ES, et al. The effect of soy phytoestrogen supplementation on thyroid status and cardiovascular risk markers in patients with subclinical hypothyroidism: a randomized, double-blind, crossover study. J. Clin. Endocrinol. Metab. 2011; 96(5):1442-9.

45. Mittal N, Hota D, Dutta P, Bhansali A, Suri V, Aggarwal N, et al. Evaluation of effect of isoflavone on thyroid economy \& autoimmunity in oophorectomised women: a randomised, double-blind, placebo-controlled trial. Indian J. Med. Res. 2011; 133(6):633-40.

46. Conrad SC, Chiu H, Silverman BL. Soy formula complicates management of congenital hypothyroidism. Arch. Dis. Child. 2004; 89:37-41.

47. Jabbar M, Larrea J, Shaw R. Abnormal thyroid function tests in infants with congenital hypothyroidism: the influence of soy-based formula. J. Am. Coll. Nutr. 1997; 16(3):280-2.

48. D'adamo CR, Sahin A. Soy foods and supplementation: a review of commonly perceived health benefits and risks. Altern. Ther. Health Med. 2014; 20 (suppl 1):39-51.

49. Bitto A, Polito F, Atteritano M, Altavilla D, Mazzaferro S, Marini H, et al. Genistein aglycone does not affect thyroid function: results from a three-year, randomized, double-blind, placebo-controlled trial. J. Clin. Endocrinol. Metab. 2010; 95(6):3067-72.

50. Messina M, Redmond G. Effects of soy protein and soybean isoflavones on thyroid function in healthy adults and hypothyroid patients: a review of the relevant literature. Thyroid. 2006; 16(3):249-58.

51. Ventura A, Ronsoni MF, Shiozawa MB, Dantas-Corrêa EB, Canalli MH, Schiavon LD, et al. Prevalence and clinical features of celiac disease in patients with autoimune thyroiditis: cross-sectional study. Med. J. 2014; 132(6):364-71.

52. Mehrdad M, Mansour-Ghanaei F, Mohammadi F, Joukar F, Dodangeh S, Mansour-Ghanaei R. Frequency of celiac disease in patients with hypothyroidism. J. Thyroid Res. 2012; 2012:1-6.

53. Caglar E, Ugurlu S, Ozenoglu A, Can G, Kadioglu P, Dobrucali, A, et al. Autoantibody frequency in celiac disease. Clinics. 2009; 64(12):1195-2000.

54. Sategna G, Solerio E, Scaglione N, Aimo G, Mengozzi G. Duration of gluten exposure in adult coeliac disease does not correlate with the risk for autoimmune disorders. Gut. 2001; 49(4):502-5.

55. Cosnes J, Cellier C, Viola S, Colombel JF, Michaud L, Sarles J, et al. Incidence of autoimmune diseases in celiac disease: protective effect of the gluten-free diet. Clin. Gastroenterol. Hepatol. 2008; 6(7):753-8.

56. Ferreira ACF, Neto JC, Silva AC, Kuster RM, Carvalho DP. Inhibition of Thyroid Peroxidase by Myrcia uniflora Flavonoids. Chem. Res. Toxicol. 2006; 19(3):351-5.

57. Chandra AK, De N. Catechin induced modulation in the activities of thyroid hormone sunth 58 esizing enzymes leading to hypothyroidism. Mol. Cell. Biochem. 2013; 374(1-2):37-48.

58. Román GC. Autism: transient in utero hypothyroxinemia related to maternal flavonoid ingestion during pregnancy and to other environmental antithyroid agents. J. Neurol. Sci. 2007; 262(1-2):15-26. 
